\title{
Children Schooling Achievements in the Course of Early Education and Their Cognitive Development
}

\author{
Natalia Józefacka Szram
}

\begin{abstract}
The study show connections between educational achievements and efficiency of basic components of executive functions (EF) understoodas short-term memory, inhibition control and set shifting. Particular research topics are concentrated in development of executive functions issue in view of age (5-, 6 years old). Study based on two groups of children from preschool class $(N=96)$ and first grade $(N=97)$, both levelled in terms of gender. This project takes into consideration relationship between EF - school achievements, controlling socio-economical status and age. Confirmatory variation analysis indicates good correlation of all investigated factors. In the second step, execution of Structural Equation Modeling (SEM) confirms that all three EF factors have significant influence on school achievements, also assumption about age finds confirmation in the data. Hypothesis about influence of sex and SES on school achievement was found insignificant.
\end{abstract}

Index Terms-Executive functions, inhibition, school achievement, switching working memory.

\section{INTRODUCTION}

Executive functions (EF), as it is a good predictor of future professional and life success and schooling achievements of children is a subject broadly brought up in literature [1], [2]. In this research the schooling achievements (SA) are understood as a measure of cognitive abilities of a child in aspects of reading, writing and mathematics. It should be added that school children not only gather knowledge but also learn society cohabitation rules and self-regulation. EF refer to a family of top down mental process needed when you have to concentrate and pay attention [3], [4] There is a general agreement that there are three cores [3], [5], [6]. Inhibition-comprehended as inhibition control, including self-control (behavioural inhibition) and control of interference (selective focus and cognitive inhibition). Working memoryandShifting - known as well as mental flexibility or mental shifting

Complex manifestations of EF can be also singled out like conclusion, problem solving or planning [7], [8] From the literature review conclusion can be drawn that executive functions are the abilities being at the base of both mental and physical health [9], [10] and are responsible for schooling and life successes [11]-[13] and also for sociological and psychological development [14], [15].

Cognitive control consists of setting on task disregarding distractions and conscious set shifting between tasks. All these abilities directly influence development of school

Manuscript received March 4, 2015; revised August 11, 2015.

Natalia Józefacka Szram is with the Maria Grzegorzewska Academy of Special Education, Poland (e-mail: natalia.szram@gmail.com). readiness in respect of cognition and culture as well as level of schooling, professional and life achievements of a human being [16].

Blair [17] draws attention to a part EF play in learning process. He stresses that $\mathrm{EF}$ are being developed under influence of pre-school and school education. In this study not only broader range of executive functions (all three base aspects) was examined but also following: definition of relation between child age, and EF level, definition of relation between child socio-economical status (SES), and EF level, definition which element of $\mathrm{EF}$ is the best predictor of the child school achievements at given stage of development.

The subject of this study enters the mainstream of researches in the field of cognitive psychology, developmental psychology and early-school pedagogics. Many research in the subject of the EF emerged already in the 90 's however it is still unknown how in time we can speak of beginnings or maturity of particular elements of executive functions. It is known that we can train them at any stage of development and that [18] in children because of high brain flexibility, the effects of such trainings are the most effective [19].

TABLE I: HYPOTHESIS OF THE STUDY

\begin{tabular}{ll} 
Hypothesis \\
\hline 1 & $\begin{array}{l}\text { The older the children the more developed EF and better their } \\
\text { schooling achievements will be }\end{array}$ \\
2 & Significant difference exists on level of EF between boys and girls \\
3 & Level of executive functions is influenced by school achievement \\
& stage \\
4 & SES is a significant variable between EF and school achievement \\
\hline
\end{tabular}

The importance of EF is extremely significant to mental and physical health, being successful in school and life and also to social and mental development [20]-[22]. Despite the fact that we do not always pay attention to those skills, they become the most visible when disrupted and produce symptoms such as absentmindedness, difficulties in planning activities, de-concentration [23]. It is thought that the activeness of the executive functions can be seen in situations requiring: stopping imposing reactions, flexible set shifting, inhibiting reception of interrupting impulses, actualizing memorized information. In turn, situations new or complicated manifest more complex regulation abilities like: planning, initiating, monitoring of own behaviour, delaying gratification [24].

Main challenge of EF research is their measurement. Individual elements of EF coexist together and currently it is not possible to measure them in their pure form because we can only see effects of their activity in a form of deviation [18]. 
Main research topic is to describe how children cognitive development proceeds at early education stage and how particular executive functions determine educational achievements. Dependent variables - age, education level, parents SES - will be taken in to consideration. Directional hypothesis were drawn according to current research results [16], [25], [26].

\section{METHOD}

\section{A. Participants}

Participants were 193 children enrolled in five kindergartens and three public schools whereof girls states $N=98$, and boys $N=95$ (kindergarten 48-girl and 48-boy; first grade 50-girl, 47-boy). There were 97 six-year-old (Min=4,9, $\mathrm{Max}=5,9, M=5,4, \mathrm{SD}=3,56)$ and 96 five-years-old kids (Min=6,3, Max=6,8 $M=6,6, \mathrm{SD}=3,47$ ). All kids were from south Poland towns. Their intelligence were normal $(\mathrm{min}=80$ $\mathrm{IQ}, \max =138 \mathrm{IQ}, M=105, \mathrm{SD}=15$ ).

\section{B. Procedure}

For each participant, we administered a battery of tasks that were divided into five sets. Each set took 15-30 min to administer. Within each set, the tasks were scheduled in a non-fixed order, with all task sets administered over 2 days to several weeks, depending on the schools'/kindergartens' logistical requirements. For all the children, the tasks were administered individually. Battery included intelligence scales, executive functions tasks and school achievement task, all tasks except IQ test were examined based on tablet special application which simulated a game. The children were examined individually at school or kindergarten in special quite room. After each set they got small reward. First of all intelligence was tested, after that executive functions, and in the end school achievements. After that their parents filled in a questionnaire regarding family socio-economical status (SES). Research took place from October till to December 2014 and it states first step of cohort-sequential research.

\section{MEASURES}

\section{A. Inteligence}

Culture neutral Cattle Inteligence Test - CTF-1R. Test directed to measure general intelligence, understood as the fluid intelligence. It consists of six subtests grouped in to two parts. First (subtests: Substitution, Mazes and Similarities) contains perception ability, attention, eye-hand coordination tasks; the second (subtests: Series, Classifications, Stencil) reasoning measuring tasks, tasks measuring detection of rules defining relationships between objects and structure complementation tasks. The tasks have non-verbal character and do not require any knowledge gathered before.

\section{B. Executive Functions}

The Corsi Block Test (tablet task). The task requires individuals to reproduce block-tapping sequences of increasing length and provides an index of immediate memory span capacity for spatial information. Individuals observe board where in the fixed intervals cubic blocks appear in sequence and at a rate set by the examiner. After the end of the presentation, individuals have to reproduce arrangement and sequence of blocks. The test measures non-verbal spatial working memory. It is a tablet computer based an arcade game style task, made and adapted to polish children ( 5 to 8 years olds) during implementation phase. In the instruction child have to show blocks in the right order.

Switching task. Requirement to sort a series of bivalent test cartoon characters (red crab or green frog). Both of them could be with or without frame. If a character is in a frame (2), participant has to sort by the colour, if there is not any frame (1) around cartoon have to sorting by shape (Fig. 1).

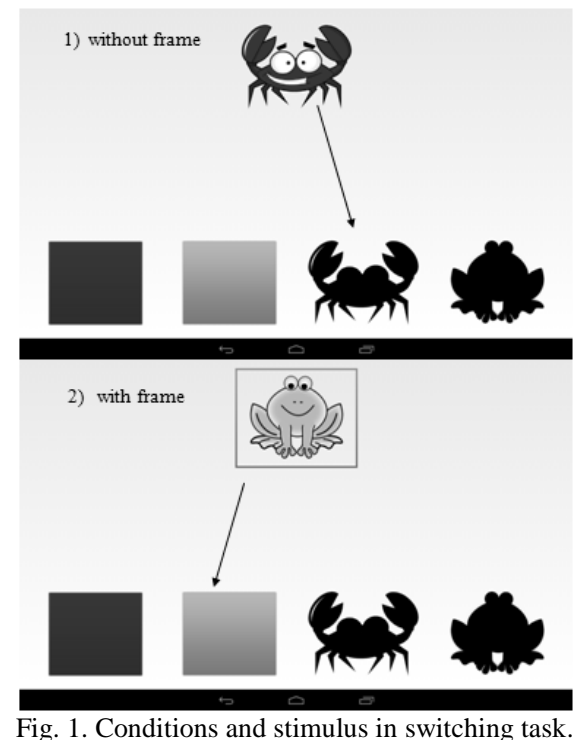

Test of Working Memory (TPR). Test consists of three task measuring three aspects of working memory:

Simultaneous storing and processing - counting span. Performing operations on the presented visual material (despite of emergence of disturbing content) and storing the results. The task is to convert the specified objects shown on the following boards (given selection criterion; conversions in the range of 1 to 5), memorize them, and then replaying their numbers in the order of exposure. Sample set consists of 2 boards. The main set consists of 2 sets of 2, 3, 4 and 5 boards (a total of 8 sets in pseudo random sequence not to jump more than two in example 2 boards, 4 boards, 3, 5, 3, 2, etc.).

Supervision - task-set switching $2 \times \mathbf{2}$. In this task, in a square divided into four fields single drawings of a girl or a boy's face (smiling face, a sad face) are displayed (clockwise). The task is to switch between the decision-making whether the face presented is a BOY (if the face appears in the upper boxes), or whether is HAPPY (if is in the lower boxes) using the same buttons symbolizing answer YES vs NO. Child hears which criterion should be applied.

Coordination - spatial short-term memory - the task consists of memorizing fields of a matrix on which individually appear the same objects (2 to 5), and then identifying those fields. The test sample starts with the two objects (ladybugs), followed by main twelve samples. They are two samples taken for subsequent levels of difficulty (from 2 to 5 objects $6 \times 6$ grid).

Shape Task (ST) based on M. Espy School Shape tool. The tool examines inhibitory control and set shift. It consists of 4 
levels (conditions): control (baseline colour naming), inhibition, blocks switch, mixed switch and interference. The tool is presented in a form of a computer game and is be adapted to polish children (5-8 years old) as a trial. The test stimulus are animated characters which vary on the dimensions, colour (blue, red) and shape (circle, square) and according to particular cues (happy/sad facial expression for condition 2 and hat/no hat in conditions 3 and 4; both in condition 5). Prior to each condition, children complete six practice runs, where they are provided verbal feedback on their performance. No feedback is provided during the Condition 1, baseline colour naming - children are advised that the characters' names are their colours (red/blue) and are asked to name 12 characters with neutral expressions as quickly and as accurately as possible as they appear sequentially on the computer screen. Condition 2, inhibition - 12 inhibit and 24 non-inhibit trials assess children's inhibitory suppression of a pre-potent verbal response. Children are instructed to name only the colours of characters with happy faces and to remain silent for characters with sad faces. Condition 3, blocked switch (12 trials), characters are depicted with neutral expressions and wearing hats. Children are instructed to name characters with hats by their shape. Condition 4, mixed switching (20 switch and 10 non-switch trials), neutral characters both with and without hats are presented and children are required to flexibly shift their responses between dimensions of colour and shape as cued. Children are allowed an unlimited time window in which to provide verbal responses.

\section{Schooling Achievements}

Test of Abilities at Start of School (TUNSS) (tablet task)It is a tool to examine school achievements of the pre-school to 2nd grade primary school pupils. This tool has friendly, adaptive form, which provides ability to adapt difficulty level to answers given by the child. Through this form the measurement is more precise, the tested child does not get bored (task is not too easy) and does not loose motivation (task is not too difficult). The test examines three types of abilities: Mathematical skills (numbers, measurements, space and shape, relations and dependencies). Writing (visual-motoric efficiency, spatial-visual efficiency, auditory-language efficiency, calligraphy and writing). Reading (auditory-language efficiency visual-auditory efficiency, reading ability).

\section{SES Questionnaire}

SES was investigated based on questionnaire filled in by one of the child's parents. There were four questions, regarding amount of years of education of mother and father, size of their home (in square meters) and amount of books at home (interval scale).

\section{RESUlts}

\section{A. Data Analysis}

The percentage of missing values was less than $5 \%$ for all variables. Missing data were replaced using the linear trend at point.

\section{B. GLM (General Linear Model)}

In order to check differences in EF between level of school (last year of kindergarten; first grade of primary school) and sex, GLM (general linear model) was used. The main effect of gender in contrast to the main effect of the level of education proved to be insignificant for all subtests, suggesting that age (and associated with this the type of education level) is more important in shaping the EF than sex. The effect of the interaction of sex / type of education also turned out to be not significant. Therefore, only the differences arising from the level of education will be presented in following (Table I). In line with the assumptions working memory capacity increases with the level of education. The best test differentiating children working memory is storage from TPR task (kindergarten $M=43,47$ school $M=58,094$ ). Inhibition was measured using two types of variables - the total sum of the points (Total) and reaction time (RT). As expected, both variables have the opposite direction to each other -Total increases with age, and the reaction time is decreased in older children. Definitely more pronounced differences in this respect can be seen when comparing reaction times than the total amount of points. This may be due to the fact that inhibition in children of this age is already quite well-formed, and tests measuring reaction time are much more sensitive. Cognitive flexibility has been tested for three types of tasks. Surprising result occurred in the Shape Task's 4th condition, where in older children the response time significantly increased. This may result from multistage form of the tasks, where the first three conditions were relatively simple and could become a form of training for the children. The last condition was much more difficult, which could result in longer reflecting on individual items. In addition, this task requires a verbal response. The child must remember the rule, slow the reaction, and denounce the category to which the figure belongs. In the Switching task, children on their own sorted the answers by pressing appropriate box. Probably the motor response inhibition is easier for older children (less impulsivity), when inhibition of verbal response is more difficult.

The results (Table II) between children attending kindergarten and children of primary school were differentiated best by operational memory components - all had a strong effect: Corsiblock $\left(F=55.923, p<0.001 \eta^{2}=\right.$ $0.228)$ Coordination $\left(F=45.12, p<0.001 \eta^{2}=0.193\right)$ Storing $\left(F=32.083, p<0.001 \eta^{2}=0.145\right)$. Strong effects were also observed in tasks measuring inhibition: Shape Task condition_2 (RT) $\left(F=45.499, p<0.001 \eta^{2}=0.194\right)$ and for Shape Task_condition_3 (RT) $\left(F=30.788, p<0.001 \eta^{2}=\right.$ $0.140)$, remaining results characterized in general with lower effect. For the cognitive flexibility construct the only strong effect was the switching task (RT) $\left(F=48.427, p<0.001 \eta^{2}=\right.$ $0.204)$. The other effects were average. It can be concluded from the above that the children at different levels of education differentiate best the tasks of working memory group and the least the tasks of the inhibition group.

\section{SEM (Structural Equation Model)}

\section{1) Model fitting}

This study shows connection between educational 
achievements, efficiency of basic components of executive functions, controlled SES and age. SEM was used to test two hypotheses: 1-EF are good predictors of school achievement, 2-SES is significant factor in the area of school achievement.

TABLE II: DESCRIPTIVE STATISTIC FOR GLM

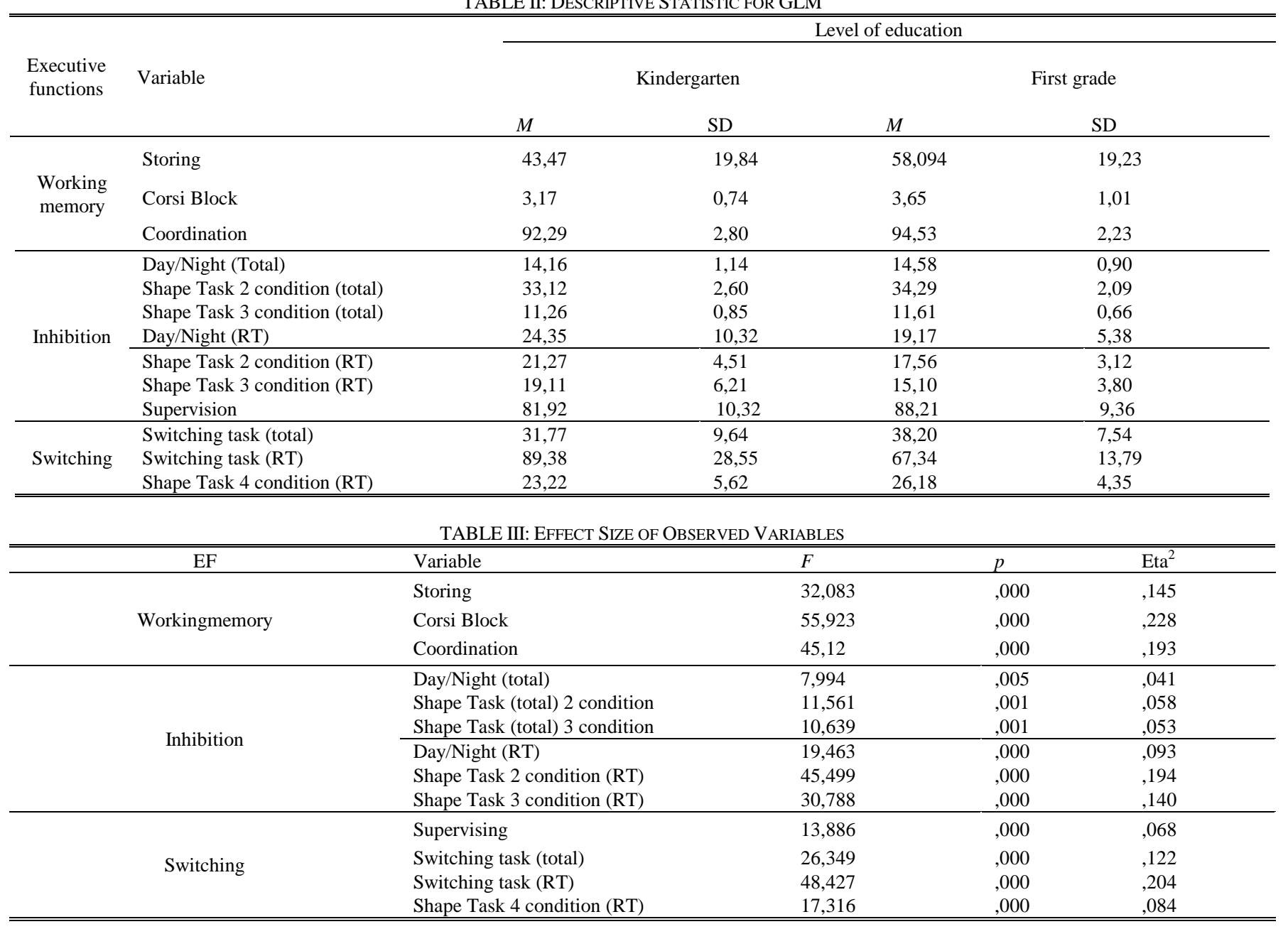

We specified a structural model to examine the relationships between $\mathrm{EF}$ and school achievement (SA) in children. The latent executive processes (inhibition, switching, and updating) were modelled on the latent SA variables (mathematic, writing, reading) because these relationships were of theoretical interest. A three-factor model of EF and a one-factor model of SA provided the best fit to the data, $\chi^{2}(108)=167,435, \mathrm{CFI}=0.945, \mathrm{RMSEA}=0,54(\mathrm{~min}=0,37$, $\max =0,69)$.

The fact that our theoretical model fits in both populations yields support that the theoretical model adequately describes the data. This means that the parameter estimates of the three part executive functions onto the school achievement can be validly interpreted.

\section{2) Model specifications}

The theoretical model consists of latent variables and indicators. Latent variables cannot be directly observed and are inferred from variables that can be directly observed: the indicators. Indicators consist of the dependent measures derived from the seven tests. Here we describe each of the latent variables, the indicators used to measure each of the latent variables, as well as the interrelations between the latent variables

The theoretical model is displayed in Fig. 1 and includes variables and the inter-correlations between these variables.
The models include three latent variables: working memory, inhibition and switching. Working memory consist of updating (TPR-storing task), updating \& spatial memory (TPR-coordination task), spatial memory (Corsi block task).Three tasks are used in inhibition assessment, however due to their better sensitivity only the reaction time data were included in this model. Additionally, simultaneous introduction of score results and reaction time together with small survey sample $(N=197)$ result in the program being unable to estimate respective relationships result values.

Two tasks derived from Shape-task. One measures simple inhibition (required withholding of reaction) (SS_2_RT), the second one measures complex inhibition (withholding of reaction and substitution with another one) (SS_3_RT). The third task belongs to Day/Night (DN_2_RT) task and it was the reaction time from second part of this task. Shifting also consist of three parts, one from switching task: total score (ST_total), one from Shape-task (condition 4), measured by reaction time (ST_RT) and third from TPR Task - the total score in Supervision Task.

As an independent latent variable, it was assumed that School Achievement consists of three observed variables concerning mathematic, writing and reading measures on standardized scales.

As a controlled variable, socio-economical status understood as education of parents measured as years of 
learning (Edu_M for mother, Edu_F for father), amount of books (interval scale) and home size (square meter) were used.

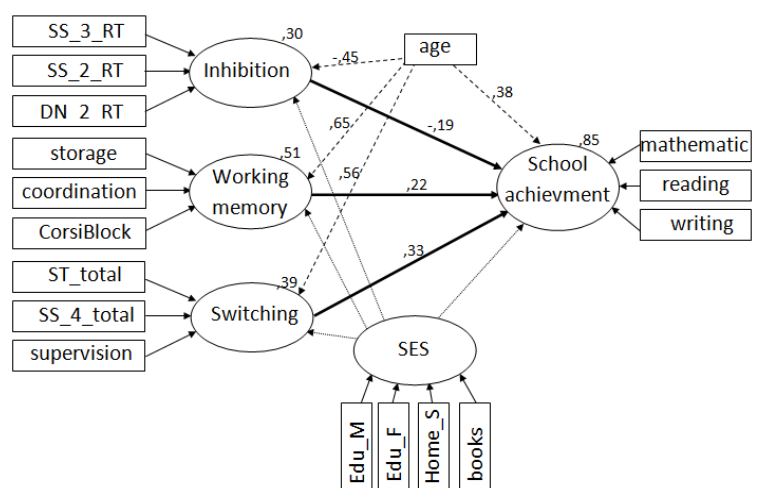

Fig. 2. SEM, relationship between inhibition, working memory, switching and school achievement, controlled age and SES. On the arrow - the effect size, under latent variables - per cent of variation.

TABLE IV: STANDARDIZED REGRESSION WEIGHT OF THE MODEL (WM-WORKING MEMORY, INH-INHIBITION, SWCH-SWITCHING, SA-SCHOOL

\begin{tabular}{lllclc}
\multicolumn{7}{c}{ ACHIEVEMENT) } \\
\hline \hline WM & \multicolumn{1}{c}{$b$} & $b$ & SD & $P$ \\
\hline Inh & $<---$ & age &, 646 &, 145 & $* * *$ \\
Swch & $<---$ & age &,- 453 &, 035 & $* * *$ \\
Swch & $<---$ & SES &, 561 &, 084 & $* * *$ \\
WM & $<---$ & SES &, 279 &, 055 &, 086 \\
Inh & $<---$ & SES &, 297 &, 098 &, 029 \\
SA & $<---$ & Inh &,- 301 &, 030 &, 024 \\
SA & $<---$ & Swch &, 337 &, 253 &, 007 \\
SA & $<---$ & WM &, 217 &, 344 &, 020 \\
SA & $<---$ & age &, 380 &, 113 &, 031 \\
SA & $<---$ & SES &, 116 &, 073 & $* * *$ \\
\hline \hline
\end{tabular}

\section{Parameter Estimates}

The estimated standardized regression weights $(\beta)$ of the hypothesis testing model (Table III) show the change in the dependent latent variable associated with one standard deviation and the change in the independent latent variable, holding all the other independent latent variables constant.The most interesting us dependencies concern working memory, inhibition and cognitive flexibility, and their relationship with school achievements. All these dependencies have proven to be important. In the model, the most important was positively correlated working memory $\beta$ $=0.22, p<0.001$. Cognitive flexibility was less significant predictor $\beta=0.163, p<0.001$, but it was also a positive relationship. As expected, the relationship between inhibition and school achievements was negative and resulted $\beta=0.168$ $p<0.05$, it is due to the fact that the inhibition was measured by reaction time, hence the lower the response time, the higher are school achievements.

Lack of significance in relation to SES school achievements in presented model $\beta=0.116 p>0.2$ can be considered as interesting. In relation to the EF SES presents a low significance in case of working memory $(\beta=0.297 p<$ $0.05)$ inhibition $(\beta=-0.301 p<0.05)$, and no significance of cognitive flexibility $(\beta=0.279 p>0.086)$. It should also be noted that each of the SES factors was statistically significant at $p<0.01$. This effect, although contrary to expectations, brings positive feedback that SES as measured by parents' education, home size and amount of books does not differentiate children in school achievement.

The last controlled factor was the age effect on both the level of school achievements as well as various aspects of executive functions. In line with the assumptions age significantly $(p<0.001)$ affects the level of memory (WM), inhibition (Inh) and cognitive flexibility (Swch), as well as school achievement(SA). The strongest relationship exists between age and working memory $(\beta=0.646)$, and the weakest with school achievements $(\beta=0.380)$.

\section{CONCLUSION}

Four basic hypotheses were provided in this research. Based on statistical analysis of GML and SEM, two initial hypotheses were accepted and two rejected. As a result of analysis, it turned out that the relationship of gender to the level of EF and SA is irrelevant, as is the level of SES.

As important emerged the influence of EF on the SA, although the strength of this relationship is average what may be a result of limited number of tests used to measure single construct. However, the influence of age on both the SA and on FW proved to be not only important but also very strong. At the end, it should be noted that this model explains $85 \%$ variations of SA.

\section{DISCUSSION}

The presented study adds some new results to the growing body of developmental and educational research supporting the key role of EF in young children's school achievements. The first of discussed assumptions was dependence of school achievements on children age, and thus the level of their education (pre-school or first grade). It is well known that aging is accompanied by a decline in a wide number of cognitive domains, including episodic memory, working memory, problem solving, and spatial abilities [27]. Concerning the changes in executive sub processes with aging, a recent review of meta-analyses [28] showed that some processes (e.g., the inhibitory process named resistance to interference) did not show age-related alterations, whereas others (e.g., shifting processes as global task switching) were negatively affected by advancing age [29]. Fisk and Sharp [30] observed an age-related decline in all of the three sub processes of the Miyake model. Similar results were confirmed in this study, age significantly differentiated not only all levels of EF, but also SA. Interestingly, subsequent ignoring to take into account the age of the structural model resulted in a worse model fit. The analysis of associations between EF and school achievement is informative in suggesting a developmental link between these skills [31]. In order to take and apply perspective, in which intervention or prevention programs are implemented, it should first be empirically established on which level of development respective part of $\mathrm{EF}$ is.

Sex was elaborated as the next variable, according to hypothesis difference in area of EF and school achievement. Citing literature usually boys characterized better level of shifting, and girls better level of working memory and 
inhibition [32]. Further [33] also administered significant differences between boys and girls in EF and mathematical achievements. It should be added that there is also no association between gender, SA and EF reported [34]. Unexpectedly negligible effect was obtained in the area of SES control, despite extensive literature speaking about major impact of SES on tests of intelligence and school achievements [35], [36], language [37], [38], attention [39]. It should be also noted that although a large body of evidence supports the linkage between SES and EF, less is known about the specific socio-economic indicators that may predict executive task performance. SES is a composite variable that includes measures of family income, occupational status, and parental education. Researchers have suggested that these indicators may have separate effects on children's developmental outcomes [40].

Probably an influence on insignificant relationship of SES and school achievement can also have employed performance indicators which should perhaps contain additional information like i.e. family income. The result may also have a relationship with the education system operating in Poland; the cited studies were developed in English and Spanish speaking countries. In Poland, private education, as well as the possibility of extra-curricular activities are not well developed, which translates into less differentiation in access to education for children of low and high SES.

This study describes well the relationships that exist in reality, but should be extended to a larger number of samples to check how the EF and school achievements relationship develops further. Interesting is the fact that if at a later date adolescent gender differences will not start to be relevant.

\section{REFERENCES}

[1] B. Wilgocka-Okoń, School Readiness, Warsaw: Academic Publishing House, Żak, 2000.

[2] L. Wiatrowska and H. Dmochowska, Child before School. School Readiness, Krakow: Oficyna Wydawnicza, Impuls, 2013.

[3] A. Diamond, "Executive funtions," Ann. Rev. of Psychology, vol. 64, pp. 135-168, Jan. 2013.

[4] K. A. Espy, "Using developmental, cognitive and neuroscience approaches to understand executive control in young children," Dev. Neuropsychol, vol. 26, pp. 379-84, 2004.

[5] A. Miyake, N. P. Friedman, M. J. Emerson, A. H. Witzki, A. Howerter, and T. D. Wager, "The unity and diversity of executive functions and their contributions to complex 'frontal lobe' tasks: A latent variable analysis," Cogn. Psychol, vol. 41, pp. 49-100, Dec. 2000.

[6] J. E. Lehto, P. Juujarvi, L. Kooistra, and L. Pulkkinen, "Dimensions of executive functioning: Evidence from children," Br. J. Dev. Psychol., vol. 21, pp. 59-80, Nov. 2005.

[7] A. Collins and E. Koechlin, "Reasoning, learning and creativity: frontal lobe function and human decision-making," PLoSBiol, vol. 10, no. 3, p. e1001293, March 2012.

[8] L. Lunt et al., "Prefrontal cortex dysfunction and "jumping to conclusions': bias or deficit?" J. Neuropsychol, vol. 6, pp. 65-78, Mar. 2012.

[9] R. D. Baler and N. D. Volkow, "Drug addiction: The neurobiology of disrupted self-control," Trends Mol Med, vol. 12, pp. 559-566, Dec. 2006.

[10] A. Diamond and N. Z. Kirkham, "Not quite as grown-up as we like to think: Parallels between cognition in childhood and adulthood," Psychological Science, vol. 16, pp. 291-297, Feb. 2005.

[11] E. Borella et al., "The specific role of inhibition in reading comprehension in good and poor comprehenders," J. Learn. Disabil, vol. 43, pp. 541-552, Oct. 2005.

[12] G. J. Duncan et al., "School readiness and later achievement," Dev Psychol, vol. 43, no. 6, pp. 1428-1446, July 2007.
[13] J. C. Davis, C. A. Marra, M. Najafzadeh, and T. Lui-Ambrose, "The independent contribution of executive functions to health related quality of life in older women," BMC Geriatrics, vol. 10, no. 1, pp. 16-23, April 2010.

[14] L. Eakin et al., "The marital and family functioning of adults with ADHD and their spouses," Journal of Attention Disorders, vol. 8, pp. 1-10, Aug. 2004.

[15] L. M. Broidy et al., "Developmental trajectories of childhood disruptive behaviors and adolescent delinquency: A six-site cross-national study," Developmental Psychology, vol. 30, pp. 222-245, Mar. 2003

[16] A. Nowotnik, "Funkcjonowanieuwagi u dzieci w wiekuwczesnoszkolnym: Grupyryzyka," Edukacja. Studia, Badania, Innowacje, vol. 1, no. 117, pp. 87-102, Jan. 2012.

[17] C. Blair, "School readiness: Integrating cognition and emotion in a neurobiological conceptualization of children's functioning at school entry," American Psychologist, vol. 57, no. 2, pp. 111-127, Feb. 2002.

[18] A. Diamond, "Activities and programs that improve children's executive functions," Current Directions in Psychological Science, vol. 21, pp. 335-341, 2012.

[19] C. Blair and A. Diamond, "Biological process in prevention and intervention: The promotion of self-regulation as a means of preventing school failure," Development Psychopatology, vol. 20, no. 3, pp. 899-911, Dec. 2008.

[20] C. Blair and R. P. Razza, "Relating effortful control, executive function, and false belief understanding to emerging math and literacy ability in kindergarten," Child Development, vol. 78, no. 2, pp. 647-663, March/April 2007.

[21] R. G. Morrison, A. A. L. Doumas, and L. E. Richland, "A computational account of children's analogical reasoning: Balancing inhibitory control in working memory and relational representation," Developmental Science, vol. 14, no. 3, pp. 516-529, Jul. 2010.

[22] B. Carretti, E. Borella, and R. D. Beni, "Does strategic memory training improve the working memory performance of younger and older adults?" Experimental Psychology, vol. 54, no. 4, pp. 311-320, 2007.

[23] A. Chuderski, Z. Stettner, and J. Orzechowski, "Bipartite models of working memory," in Proc. the 30th Annual Conference of the Cognitive Science Society, Austin, TX: Cognitive Science Society, 2008, pp. 1531-1536.

[24] J. Fryt, Executive Function and Self Regulation in Children Suffer from Asthma or Diabetes, Warsaw: Academic Publishing House Żak, 2013.

[25] R. Dolata, "Is it good born in Januray? Biological age and exam's outcome," presented at the XVIII Konferencja Diagnostyki Edukacyjnej, Wrocław, Sept 21-23, 2012.

[26] A. Klopik, "Six years old children in Poland," Kielce: 2006.

[27] T. Hedden and J. D. Gabrieli, "Insights into the ageing mind: A view from cognitive neuroscience," Nature, vol. 5, pp. 87-96, Feb. 2004.

[28] P. Verhaeghen et al., "Aging and dual-task performance: A meta-analysis," Psychol Aging, vol. 18, no. 3, pp. 443-460, Sept. 2003.

[29] P. Verhaeghen and J. Cerella, "Aging, executive control, and attention: A review of meta-analyses," Neuroscience and Biobehavioral Reviews, vol. 26, pp. 849-857, Nov. 2002.

[30] J. E. Fisk and C. A. Sharp, "Age-related impairment in executive functioning: updating, inhibition, shifting, and access," J Clin Exp Neuropsychol, vol. 26, no. 7, pp. 874-90, Oct. 2004.

[31] J. A. Welsh et al., "The development of cognitive skills and gains in academic school readiness for children from low income families," Journal of Educational Psychology, vol. 102, pp. 43-53, Feb. 2010.

[32] E. W. Skogli et al., "ADHD in girls and boys - Gender differences in co-existing symptoms and executive function measures," $B M C$ Psychiatry, vol. 13, no. 298, Nov. 2013.

[33] C. Clark et al., "Charting early trajectories of executive control with the shape school," Developmental Psychology, vol. 49, no. 8, pp. 1481-1493, Aug. 2013.

[34] H. Memisevic and O. Sinanovic, "Executive function in children with intellectual disability-the effects of sex, level and aetiology of intellectual disability," Journal of Intellectual Disability Research, vol. 58, no. 9, pp. 830-837, Sep 2014.

[35] C. T. Ramey and F. A. Campbell, "Poverty, early childhood education, and academic competence: The Abecedarian experiment," Children Reared in Poverty, NY: Cambridge University Press, 1991, pp. 190-221.

[36] J. R. Smith, J. Brooks-Gunn, and P. Klebanov, "Consequences of living in poverty for young children's cognitive and verbal ability and early school achievement," Consequences of Growing up Poor, New York: Russell Sage Foundation, 1997, pp. 132-189. 
[37] E. Hoff, "The specificity of environmental influence: Socioeconomic status affects early vocabulary development via maternal speech," Child Development, vol. 74, no. 5, pp. 1368-1378, Sep.-Oct. 2003.

[38] E. Hoff andC. Tian, "Socioeconomic status and cultural influences on language," Journal of Communication Disorders, vol. 38, pp. 271-278, Jul-Aug 2005.

[39] E. Mezzacappa, "Alerting, orienting, and executive attention: Developmental properties and socio demographic correlates in an epidemiological sample of young, urban children," Child Development, vol. 75, no. 5, pp. 1373-1386, Sep.-Oct. 2004.

[40] G. J. Duncan and K. A. Magnuson, "Off with hollings head: Socioeconomic resources, parenting and child development," Socioeconomic Status, Parenting and Child Development, Mahwah, NJ: Erlbaum, 2003, pp. 83-106.

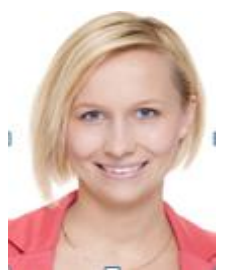

Natalia Józefacka Szram was born in Ruda Śląska, Poland. She got the master of clinical child psychology from University of Social Sciences and Humanites in 2013. She is a PhD student in the Maria Grzegorzewska Academy of Special Education in field of educational sciences.

She worked as a psychologist in Early Intervention Center and Living Psychiatric Ward for children. She is a lecturer in the Maria Grzegorzewska Academy of Special Education in field of educational siences.

Her research interests include developmental and cognitive psychology. Her major field of study isresearch in area of executive function and school achievement development. 